\title{
Esophageal lesions herald widely metastatic disease
}

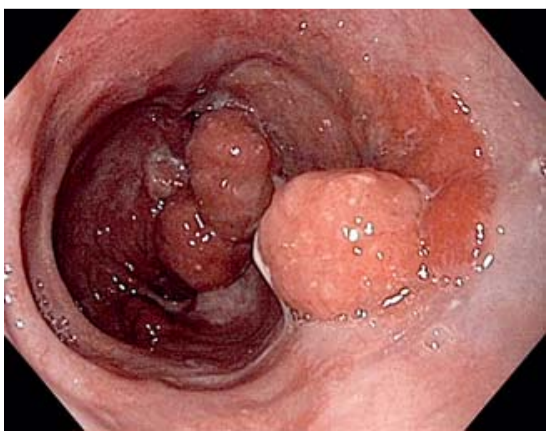

Fig. 1 Endoscopic view of the mid to distal esophagus showing multiple polypoid lesions.

A 59-year-old man with chronic hepatitis $\mathrm{C}$ and chronic obstructive pulmonary disease presented with an 8-month history of progressive solid food dysphagia, voice hoarseness, and weight loss. Prior ENT evaluation had revealed left vocal cord paralysis, with referral to gastroenterology. An upper endoscopy showed multiple polypoid masses in the mid and distal esophagus ( $\bullet$ Fig. 1, $\bullet$ Video 1 ).

Biopsies demonstrated moderately differentiated adenocarcinoma of unknown primary ( $\bullet$ Fig. 2).

Similar cells were found on fine-needle aspiration of the right superior chest wall (๑ Fig. 3).

A subsequent positron emission tomography (PET) scan revealed widely metastatic disease to the liver, bone, adrenal glands, and muscles ( $\bullet$ Fig. 4).

Polypoid neoplasms, although common in the colon, are rare in the esophagus and when found are associated with Barrett's adenocarcinoma [1]. In addition, as a further distinction, our patient has multiple polypoid lesions and diffuse metastasis throughout the body. Apart from atypical adeno/squamous cell carcinomas, the differential diagnosis for multiple esophageal malignant lesions includes primary malignant melanoma, small and large cell carcinoma, and metastatic disease. Our case illustrates the difficulty in estimating the underlying pathology of Barrett's lesions solely based on the mucosal pit and microvessel pattern. Despite the use of

\section{Video 1}

Video demonstrating the endoscopic examination of the upper oesophagus.

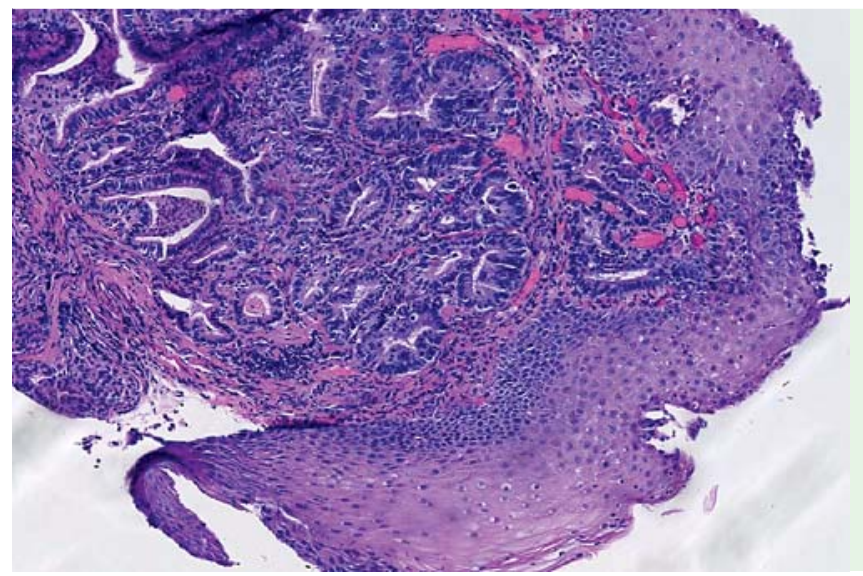

Fig. 2 Esophageal biopsy sample showing moderately differentiated adenocarcinoma.

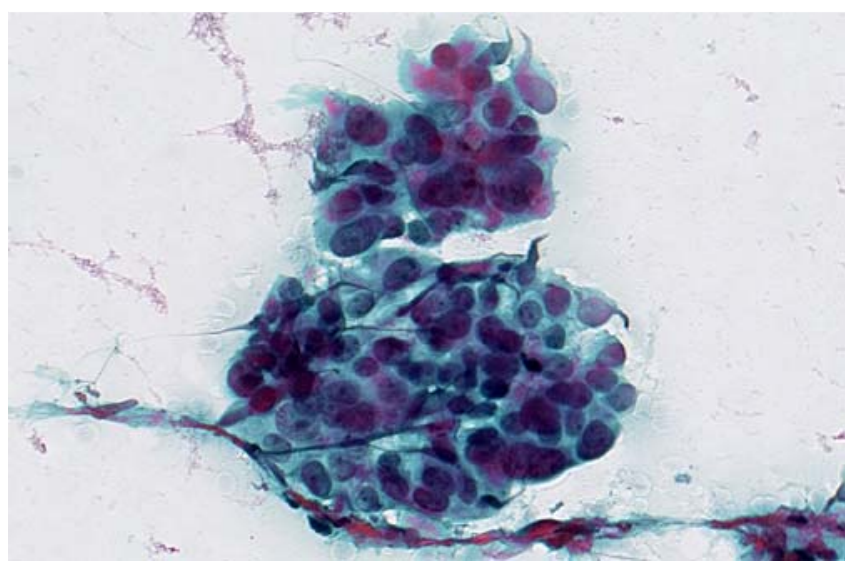

Fig. 3 Right superior chest wall fine-needle aspiration demonstrating similar cells to the esophageal biopsy specimen.

image-enhanced endoscopy, the mucosal patterns of the lesions were not significantly chaotic as has been reported $[2,3]$. The histology, showing high grade moderately differentiated adenocarcinoma, also did not seem to offer a satisfactory explanation for our patient's clinical findings, since differentiated lesions are less likely to metastasize. An explanation could be related to the unique mucosal penetration of esophageal lymphatics, which is very different from the rest of the gastrointestinal tract where it usually stops at the submucosa. The aggressive nature of superficial esophageal lesions has also been described as having an increased potential to metastasize to distant as opposed to local lymph nodes [4]. Our case highlights the continued importance for finding more effective screening modalities for Barrett's esophagus.

\section{Competing interests: None}

Endoscopy_UCTN_Code_CCL_1AB_2AC_3AB

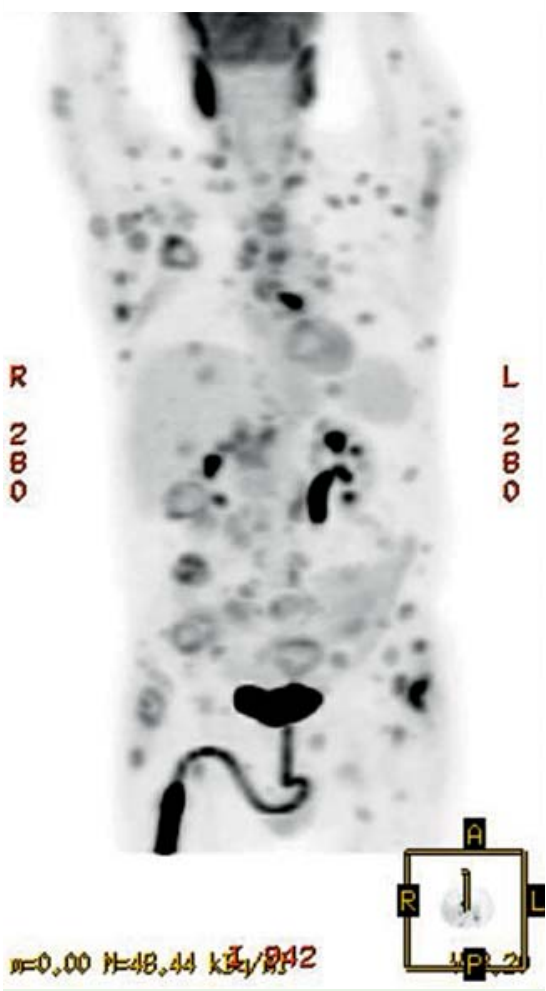

Fig. 4 Positron emission tomography (PET) scan noting widely metastatic disease. 
M. Krier ${ }^{1,2}$, T. Sato ${ }^{1}$, R. Soetikno ${ }^{1}$, T. Kaltenbach ${ }^{1}$

1 Gastrointestinal Endoscopy Unit, Veterans Affairs Palo Alto Health Care System, Palo Alto, California, USA

2 Department of Gastroenterology, Stanford University, Stanford, California, USA

\section{References}

1 Ell C, May A, Gossner L et al. Endoscopic mucosal resection of early cancer and highgrade dysplasia in Barrett's esophagus. Gastroenterology 2000; 118: 670-677

2 Hamamoto $Y$, Endo T, Nosho $K$ et al. Usefulness of narrow-band imaging endoscopy for diagnosis of Barrett's esophagus. J Gastroenterol 2004; 39: 14-20

3 Yoshida T, Inoue H, Usui S et al. Narrow-band imaging system with magnifying endoscopy for superficial esophageal lesions. Gastrointest Endosc 2004; 59: 288 - 295

4 Matsubara T, Ueda M, Abe T et al. Unique distribution patterns of metastatic lymph nodes in patients with superficial carcinoma of the thoracic oesophagus. Br J Surg 1999; 86: 669

\section{Bibliography}

DOI $10.1055 / \mathrm{s}-0030-1255642$

Endoscopy 2010; 42: E251 - E252

(c) Georg Thieme Verlag KG Stuttgart · New York . ISSN 0013-726X

\section{Corresponding author}

\section{Krier, MD}

Veterans Affairs Palo Alto Health Care System Gastroenterology 3801 Miranda Ave Gl-111 Palo Alto CA 94034

USA

Fax: +650-493-5000

mjkrier@stanford.edu 